ВЛИЯНИЕ ЭКЗОГЕННОГО МЕЛАТОНИНА НА ОКСИДАТИВНЫЙ СТАТУС

И СОСТОЯНИЕ ПЕРЕКИСНОГО ОКИСЛЕНИЯ БЕЛКОВ У КРЫС С МОДЕЛЬЮ АЛИМЕНТАРНОГО ОЖИРЕНИЯ

\author{
( ) В.В. Давыдов, Д.В. Медведев, Д.Р. Шодиев*, М.С. Некрасова
}

Рязанский государственный медицинский университет им. акад. И.П. Павлова, Рязань, Россия

Обоснование. Действию активных форм кислорода (АФК) подвергаются не только липиды, но и белки, окислительная модификация которых приводит к изменению их нативной конформации с образованием крупных агрегатов, что вызывает инактивацию ферментов, нарушает метаболизм, структуру и функционирование клеток. Кроме того, нарастает интерес к изучению гормона шишковидной железы мелатонина, а также его синтетических аналогов как ведущих факторов протекции окислительного стресса, возникающего при нарушении физиологических ритмов, в том числе и при ожирении. Особенности окислительной модификации белков (ОМБ) при алиментарном ожирении, а также условия, влияющие на данный процесс, в отличие от перекисного окисления липидов (ПОЛ), изучены недостаточно, что и обусловило необходимость выполнения данного исследования.

Цель. Оценить действие экзогенного мелатонина на оксидативный статус организма и особенности ОМБ у крыс с моделью алиментарного ожирения.

Методы. Исследование проводилось на 27 белых крысах-самцах линии Wistar массой тела 160-180 г. Животные были разделены на 3 серии по 9 особей в каждой: 1 серия - интактные животные; 2 серия - животные с алиментарным ожирением и последующим введением 0,9\% раствора хлорида натрия в объеме 2 мл в течение 12 дней; 3 серия - животные с алиментарным ожирением с последующим введением мелатонина в дозе 2 мг/кг в течение 12 дней. Алиментарное ожирение воспроизводилось путем скармливания животным высококалорийной углеводно-жировой пищи, состоящей из лабораторного корма «Ассортимент Агро» (42,5\%), сливочного масла (25\%) и сладкого сгущенного молока (32,5\%) в течение 7 нед. Определяли максимальную физическую работоспособность и устойчивость крыс к тяжелой гипобарической гипоксии. ОМБ определялась методом R. Levine в модификации Е.Е. Дубининой. Кроме этого, определяли маркер ПОЛ-ТБК-реактивные продукты (малоновый диальдегид (МДА)).

Результаты. Установлено, что ОМБ при алиментарном ожирении осуществляется неспецифично, что отражается в увеличении площадей абсорбции света (как видимого, так и ультрафиолетового спектра) альдегид- и кетондинитрофенилгидразонами. Параллельно с этим отмечается выраженное повышение концентрации ТБК-реактивных продуктов в сыворотке крови при данной патологии, а также значимое снижение устойчивости крыс к тяжелой гипобарической гипоксической гипоксии и максимальной физической нагрузке. Ежедневное введение суспензии мелатонина в дозе 2 мг/кг крысам с алиментарным ожирением в течение 12 дней приводит к значительному снижению концентрации ТБК-реактивных продуктов, однако на ОМБ существенным образом не влияет. Также стоит отметить, что изменений в функциональной активности крыс после применения препарата не наблюдалось, что говорит о низких в данной концентрации адаптивных возможностях мелатонина.

Заключение. Алиментарное ожирение у крыс, моделируемое содержанием животных на высококалорийной углеводно-жировой диете, приводит к увеличению доли висцерального жира в организме, повышению активности ОМБ в виде увеличения уровня карбонильных производных, к значительному возрастанию концентрации ТБК-реактивных продуктов (МДА), а также к существенному снижению устойчивости крыс к тяжелой гипобарической гипоксической гипоксии и максимальной физической нагрузке. При введении суспензии мелатонина в дозе 2 мг/кг в течение 12 дней отмечался не изменяющийся стабильно высокий уровень карбонильных производных в сравнении с интактной серией, что можно объяснить необходимостью использования большей концентрации препарата и/или увеличения периода его применения, но это требует дальнейшего изучения.

КЛЮЧЕВЫЕ СЛОВА: ожирение, оксидативный стресс, перекисное окисление белков, мелатонин.

\title{
INFLUENCE OF EXOGENOUS MELATONIN ON THE OXIDATIVE STATUS AND THE STATE OF PEROXIDATION OF PROTEINS IN A RAT MODEL OF ALIMENTARY OBESITY
}

(๖) Victor V. Davydov, Dmitry V. Medvedev, Dmitry R. Shodiev*, Marina S. Nekrasova

Ryazan State Medical University, Ryazan, Russia

Not only lipids, but also proteins are exposed to the action of reactive oxygen species (ROS). Oxidative modification of proteins (PBS) leads to a change in their native conformation with the formation of large aggregates, it causes inactivation of enzymes, disrupts the metabolism and functioning of cells. In addition, there is a growing interest in studying the hormone of the pineal gland called melatonin, as well as its synthetic analogues as the leading protection factors in the oxidative stress conditioned by disturbed physiological rhythms, including obesity. The peculiarities of protein peroxidation in the case of 
alimentary obesity, as well as the conditions affecting to this process, in contrast to lipid peroxidation (LPO), have not been studied sufficiently, that has determined the purpose of this study.

Aim. To evaluate the effect of exogenous melatonin on the oxidative status and features of PBS in rats with alimentary obesity. Methods. The study was conducted on 27 white Wistar male rats with body weight 160-180 grams. Animals were divided into 3 series of 9 rats in each: 1 series - intact animals; 2 series - animals with alimentary obesity, followed by the introduction of $0,9 \%$ sodium chloride solution in a volume of $2 \mathrm{ml}$ for 12 days; 3 series - animals with alimentary obesity followed by melatonin administration at a dose of $2 \mathrm{mg} / \mathrm{kg}$ rats for 12 days. Alimentary obesity was reproduced by feeding animals with high-calorie carbohydrate-fatty food, consisting of a laboratory feed "Assortment Agro" (42.5\%), butter (25\%) and sweet condensed milk (32.5\%) for seven weeks. The maximum physical working capacity and resistance of rats to severe hypobaric hypoxia were determined. PBS was determined by the method of R. Levine in the modification of E.E. Dubinina. In addition, the lipid peroxidation marker - TBA-reactive products (malonic dialdehyde MDA) was determined.

Results. It has been established that the PBS in alimentary obesity is not specific, it is reflected in the increase in the areas of absorption of light from both the visible and ultraviolet of aldehyde and ketondinitrophenylhydrazones. In parallel with this, there was a marked increase in the concentration of TBA-reactive products in the blood serum in this pathology, as well as a significant decrease in the resistance of rats to hypobaric hypoxic hypoxia and maximum physical activity. The daily administration of a $2 \mathrm{mg} / \mathrm{kg}$ melatonin suspension to rats with alimentary obesity for 12 days leads to a significant decrease in the concentration of TBA-reactive products, however, the PBS is not significantly affected.

Conclusion. Alimentary obesity in rats, simulated by the maintenance of animals on a high-calorie carbohydrate-fat diet, leads to an increase in the proportion of visceral fat in the body, an increase in the activity of PBS in the form of an increase in the level of carbonyl derivatives, a significant increase in the concentration of MDA, and a significant decrease in the stability of rats to hypobaric hypoxic hypoxia and maximum physical activity. When a melatonin suspension was administered at a dose of $2 \mathrm{mg} / \mathrm{kg}$ for 12 days, a stable high level of carbonyl derivatives was observed, in comparison with the intact series, which was explained by the need to use a greater concentration of the drug to increase its exposure time, which requires further study.

KEYWORDS: obesity, oxidative stress, protein peroxidation, melatonin.

\section{ОБОСНОВАНИЕ}

По данным ВОЗ, в 2014 г. в мире насчитывалось около 1,9 млрд людей, имеющих избыточный вес. В России избыток массы тела имеется у 60\% женщин и 50\% мужчин старше 30 лет, а 30\% населения страдают ожирением. Ожирение приводит к снижению и даже к утрате работоспособности, частой госпитализации данной группы населения из-за развития клинических осложнений (сахарный диабет 2 типа, артериальная гипертензия, сердечная недостаточность и др.) [1]. Накопившиеся знания о процессах метаболизма различных питательных веществ при ожирении говорят о полиэтиологической и полипатогенетической природе их нарушений. Немаловажная роль при этом отводится процессам свободнорадикального окисления.

Многочисленными работами было показано, что ожирение сопровождается оксидативным стрессом, характеризующимся нарушением равновесия в системе прооксиданты-антиоксиданты в сторону активации свободнорадикального перекисного окисления, которое приводит к повреждению биологических мембран клеток и внутриклеточных органелл, определяющих их морфологическую целостность, рецепцию, ионную проницаемость и транспорт метаболитов [2].

Действию активных форм кислорода (АФК) подвергаются не только липиды, но и белки $[3,4]$. У белков фрагментируются их молекулы, изменяется нативная конформация с образованием крупных агрегатов, что приводит к инактивации ферментов, а это, в свою очередь, нарушает метаболизм и функционирование клеток [5]. Имеются исследования, подтверждающие, что при ряде форм патологии вначале именно белки подвергаются окислительной модификации [6, 7]. Продукты перекисного окисления белков (ПОБ) имеют длительный период распада и большую стабильность по сравнению с продуктами пе- рекисного окисления липидов (ПОЛ), что и делает их надежным показателем активации свободнорадикального окисления [8-11].

В настоящее время проводятся научные работы по поиску веществ, в том числе и антиоксидантов, ослабляющих образование как продуктов ПОЛ, так и продуктов ПОБ [12]. Для этих целей нами был использован препарат мелатонина Мелаксен. Мелатонин, как общеизвестно, является основным вырабатываемым эпифизом гормоном, образование которого подвержено суточной периодичности с максимальной выработкой в темное время суток (с 21:00 до 7:30 у человека и с 13:00 до 18:00 у крыс) [13]. Основная функция данного гормона - модулирующее влияние на циркадную организацию физиологических процессов и обеспечение синхронизации биологических ритмов организма с ритмами окружающей среды. В частности, имеются данные о наличии у мелатонина антиоксидантного действия, заключающегося в связывании свободных радикалов, усилении активности антиоксидантных ферментов и потенцировании действия других эндогенных антиоксидантов [14, 15].

\section{ЦЕЛЬ}

Оценить действие экзогенного мелатонина на оксидативный статус и состояние ОМБ у крыс с моделью алиментарного ожирения.

\section{МЕТОДЫ}

Исследование проводилось на 27 белых крысах самцах линии Wistar массой тела 160-180 г. Животные были разделены на 3 серии по 9 особей в каждой: 1-я серия - интактные животные; 2-я серия - животные с алиментарным ожирением без введения мелатонина; 3-я серия - животные с алиментарным ожирением с вве- 
дением мелатонина. Все исследуемые крысы находились в виварии в течение 2,5 мес.

Алиментарное ожирение (2-я и 3-я серии) воспроизводилось путем скармливания животным в течение 7 нед высококалорийной углеводно-жировой пищи, состоящей из лабораторного корма «Ассортимент Агро» (42,5\%), сливочного масла (25\%) и сладкого сгущенного молока (32,5\%) [16]. Диета содержала белки - 9,28\%, жиры - 25,52\%, углеводы - 20,1\%. На каждую особь в сутки приходилось по 40 г такой пищи. Животные без ожирения получали 40 г лабораторного корма «Ассортимент Агро», содержащего 9,2\% белков, 2\% жиров, 4,4\% углеводов. Препарат мелатонина Мелаксен вводили через 5 нед с начала моделирования ожирения животным 3-й серии ежедневно в течение 12 дней орально в дозе 2 мг/кг массы тела с помощью металлического зонда 1 раз в день в период между 13:00 и 18:00 ч. Препарат предварительно растворяли в эквивалентном количестве 0,9\% раствора хлорида натрия с образованием суспензии. Животным 2-й серии через 5 нед с начала моделирования ожирения ежедневно на протяжении 12 дней перорально вводили 0,9\% раствор хлорида натрия. Во время моделирования ожирения у животных еженедельно регистрировали изменение массы тела (на электронных весах) в момент введения препарата в исходном состоянии и через 12 дней его ежедневного применения.

В начале и конце эксперимента (после забора крови для определения биохимических показателей) определяли максимальную физическую работоспособность крыс (плавательная проба до третьего погружения животного под воду) и их устойчивость к тяжелой гипобарической гипоксической гипоксии (до момента возникновения клонических судорог). Максимальная физическая работоспособность определялась по продолжительности плавания крыс с грузом у корня хвоста (5\% от массы тела) в резервуаре большого объема, заполненного водой с температурой $21^{\circ} \mathrm{C}$. Устойчивость животных к гипобарической гипоксической гипоксии определялась с помощью аппарата Комовского.

ОМБ определялась методом R. Levine в модификации Е.Е. Дубининой [17]. Метод основан на взаимодействии окисленных аминокислотных остатков с 2,4-динитрофенилгидразином с образованием динитрофенилгидразонов, обладающих специфическим спектром поглощения в видимой и ультрафиолетовой областях спектра.
Кроме того, определяли маркер ПОЛ-ТБК (тиобарбитуровой кислоты)-реактивные продукты. Данный метод определения основан на реакции малонового диальдегида (МДА) с ТБК с образованием триметилового комплекса, придающего раствору розовое окрашивание [18].

\section{ЭТИЧЕСКАЯ ЭКСПЕРТИЗА}

Все работы с подопытными животными проводились в соответствии с «Международными рекомендациями по проведению медико-биологических исследований с использованием животных» (1985) и приказом Министерства здравоохранения РФ №267 от 19.06.2003 г. «Об утверждении правил лабораторной практики».

\section{СТАТИСТИЧЕСКИЙ АНАЛИЗ}

Статистическая обработка данных проводилась с помощью программы Statsoft Statistica 6.0. Соответствие выборок нормальному распределению проверяли с помощью критерия Шапиро-Уилка. Так как распределение величин показателей соответствовало нормальному, для определения статистической значимости в независимых групnах использовали однофакторный дисперсионный анализ (ANOVA) и критерий Ньюмена-Кейлса, а в зависимых группах - ANOVA повторных измерений и критерий Ньюмена-Кейлса повторных измерений. Статистически значимыми считали отличия при $\mathrm{p} \leq 0,05$ [19].

\section{РЕЗУЛЬТАТЫ}

При потреблении крысами 2-й и 3-й серии высококалорийной пищи было установлено значительное увеличение их массы тела (более $20 \%$ от первоначальной) (рис. 1; ***1-2 p=0,009; ***1-3 p=0,009). Прирост массы тела у крыс 2-й и 3-й серий по сравнению с исходной величиной был статистически значимым со 2-й недели потребления высококалорийного корма (рис. 1 ; ${ }^{*} 2 \mathrm{p}=0,039$; **3 p=0,048). У крыс 1-й серии наблюдалась постепенная прибавка массы тела, что объясняется ростом и взрослением крыс, а также благоприятными условиями их содержания в виварии. Данная тенденция наблюдалась и в наших предыдущих работах [20]. При вскрытии животных была выявлена значительная разница в общем количестве внутрибрюшного и подкожного жира между

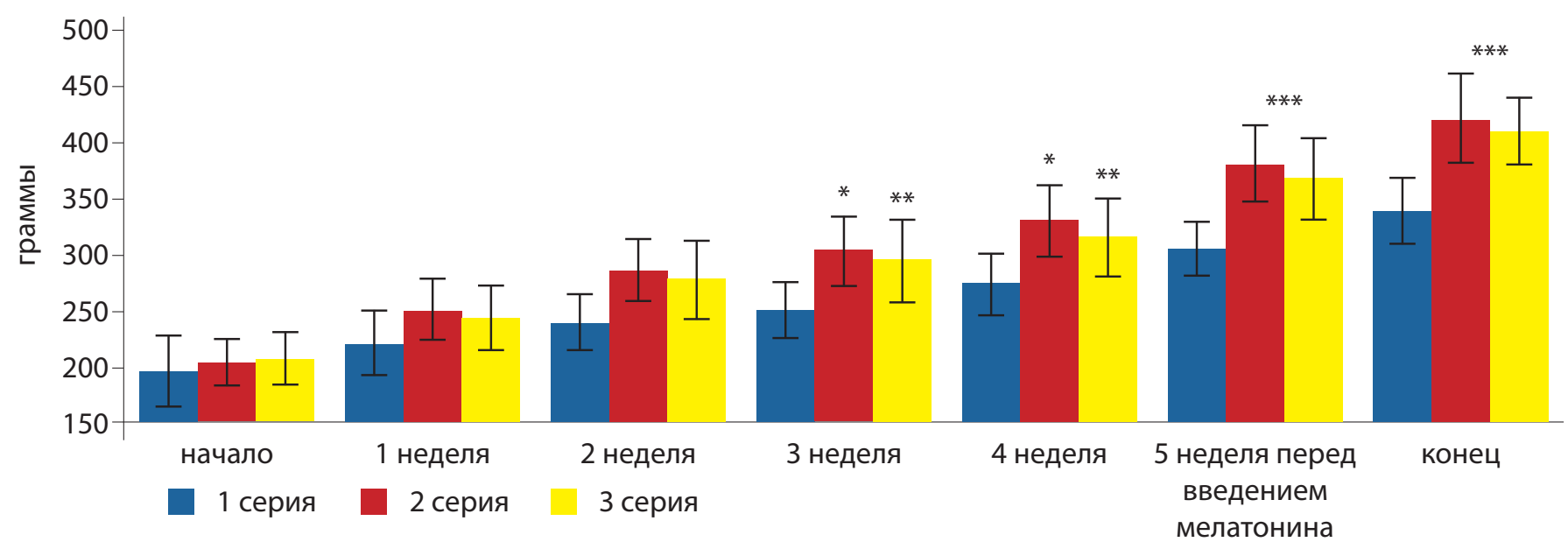

Рис. 1. Динамика изменений массы тела у крыс 1-3 серий 


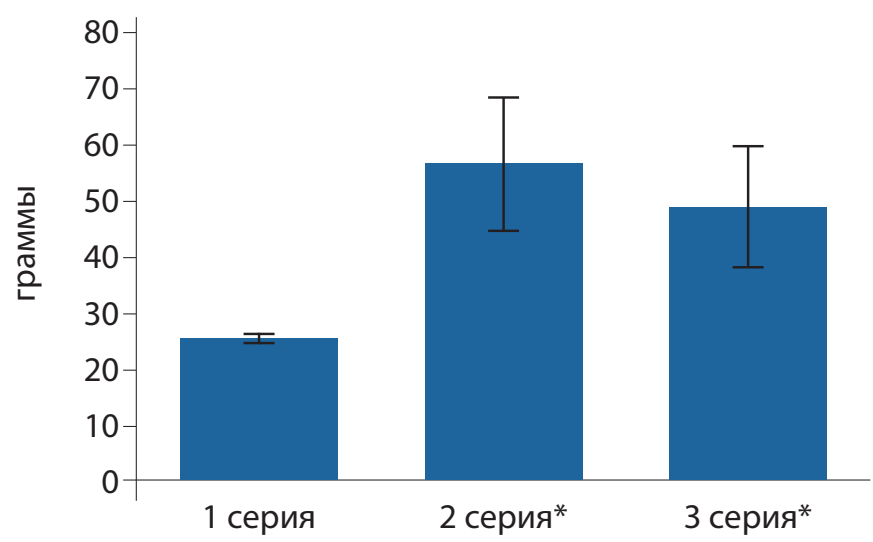

Рис. 2. Количество жира у крыс трех серий

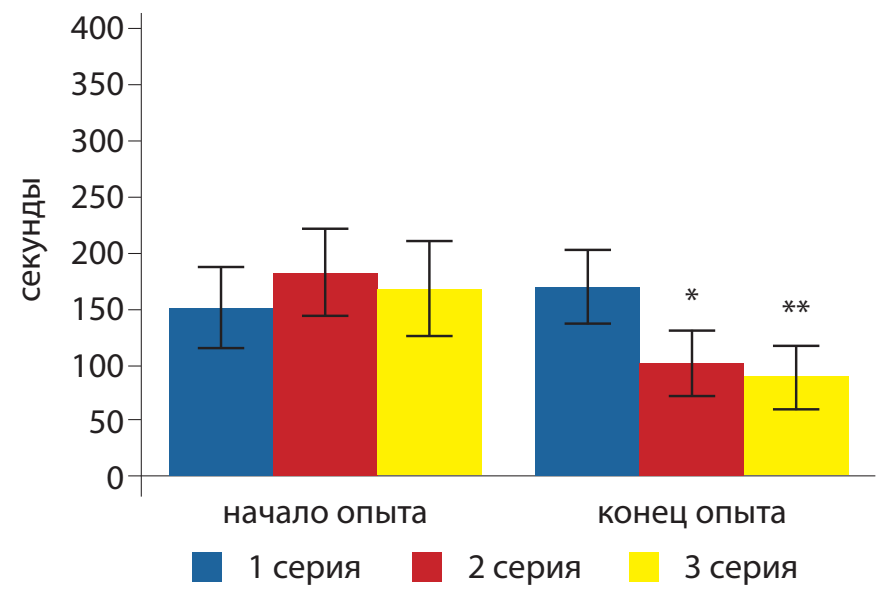

Рис. 3. Динамика изменения устойчивости крыс всех серий к гипобарической гипоксической гипоксии

интактной серией и сериями с ожирением $\left({ }^{*} 1-2 \mathrm{p}=0,008\right.$; **1-3 p=0,009) (рис. 2).

Проведенные нами тесты, отражающие физическую работоспособность и гипоксическую выносливость подопытных крыс (рис. 3 и 4), показали значительное снижение выносливости крыс с алиментарным ожирением в сериях 2 и 3, по сравнению с животными 1-й серии (рис. 3; *1-2 p=0,049; **1-3 p=0,048; рис. 4 * $\mathrm{p}=0,047$; $\left.{ }^{* *} \mathrm{p}=0,009\right)$. Это, очевидно, связано с повышением внутрибрюшного и внутригрудного давления в связи с избыточным отложением жира в брюшной полости и высоким стоянием диафрагмы, что затрудняет работу сердца и уменьшает дыхательную экскурсию грудной клетки, а также снижает эластичность самой легочной ткани, что приводит к снижению вентиляции легких, наруше-

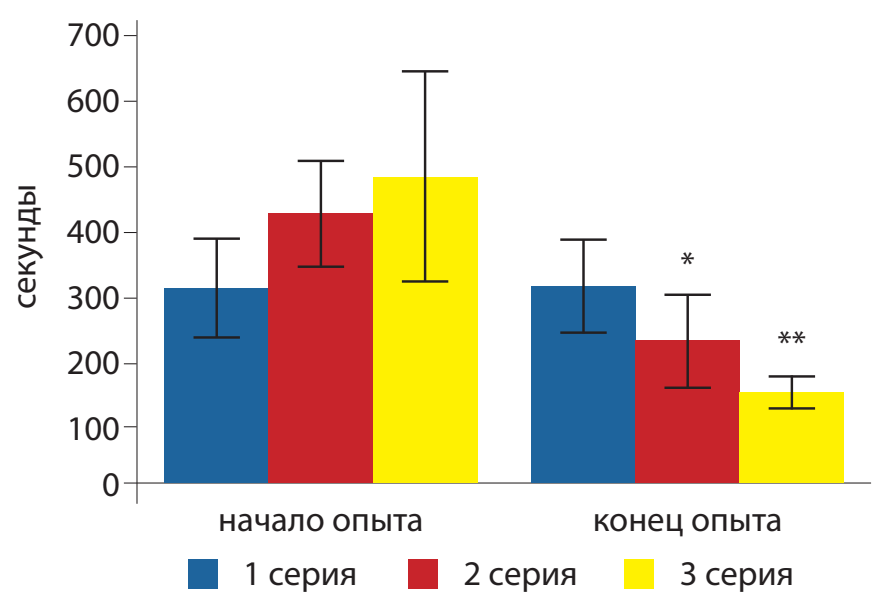

Рис. 4. Динамика изменения продолжительности плавательной пробы крыс всех серий

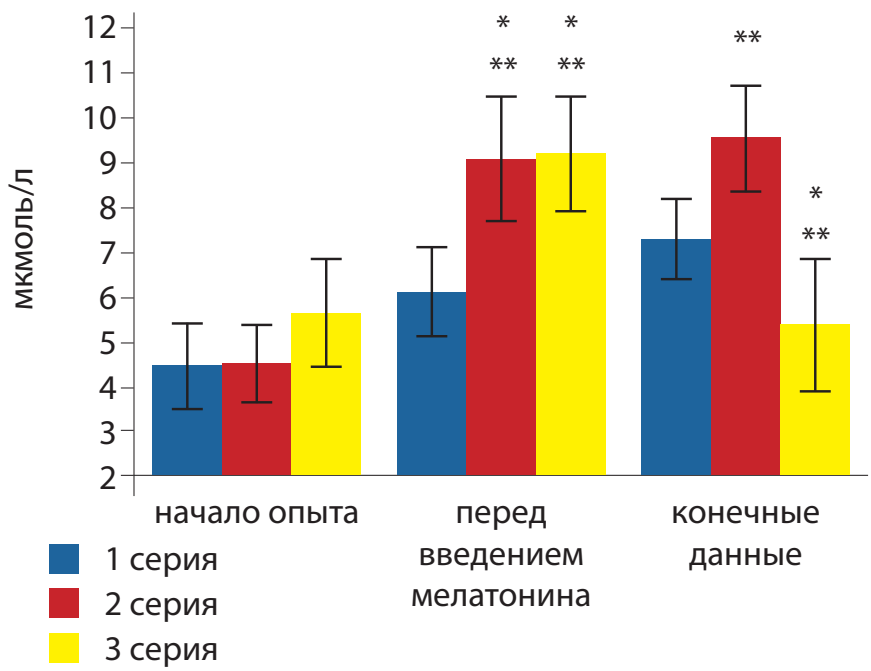

Рис. 5. Изменение концентрации ТБК-реактивных продуктов в сыворотке крови у крыс 1-3 серий

нию их газообмена, а в итоге к - дыхательной недостаточности [21].

У крыс с алиментарным ожирением (серии 2 и 3) отмечалось значительное увеличение концентрации ТБК-реактивных продуктов в сыворотке крови по сравнению с исходными данными как внутри этих серий (* $\mathrm{p}=0,008)$, так и по отношению к интактной серии (рис. 5; **1-2 p=0,047; **1-3 p=0,048). Введение препарата мелатонина у крыс 3-й серии привело к значительному снижению концентрации в крови ТБК-реактивных продуктов (рис. 5; * $\left.\mathrm{p}=0,009 ;{ }^{* *} 2-3 \mathrm{p}=0,006\right)$, что коррелирует с полученными ранее результатами других исследователей [22].

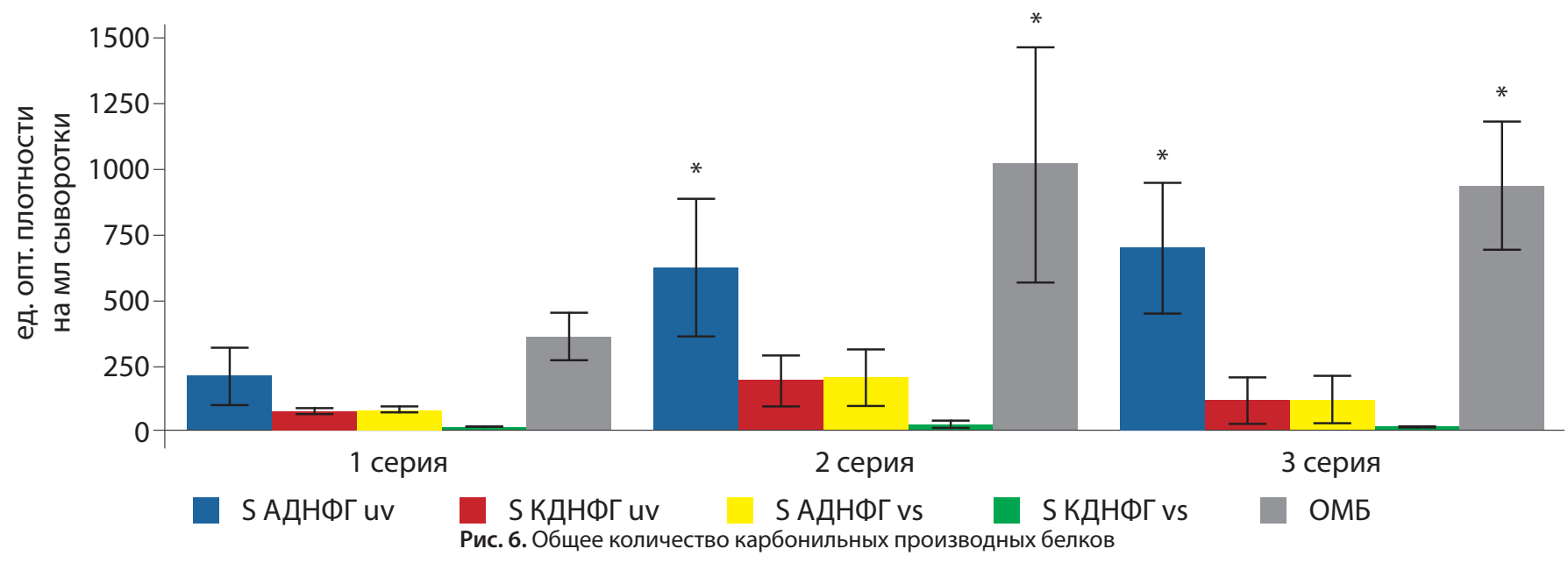




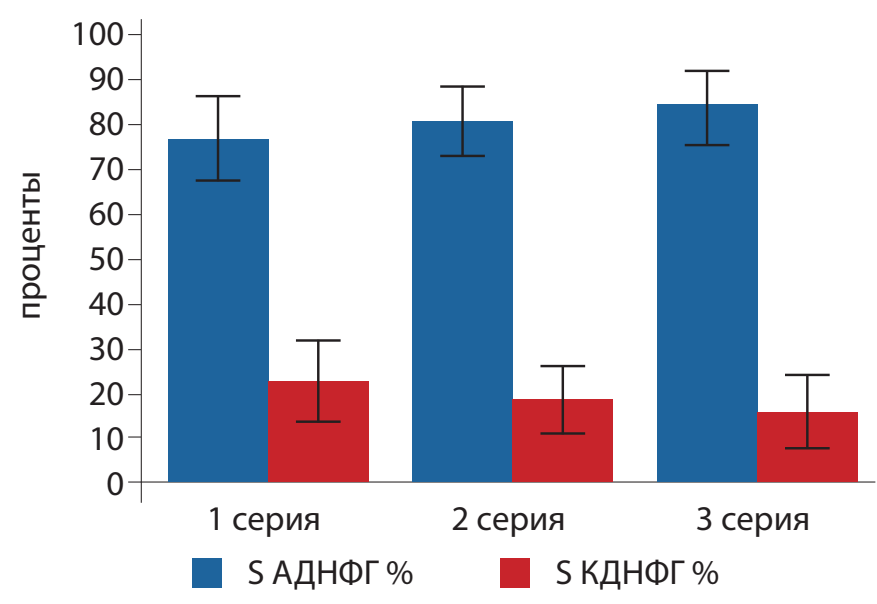

Рис. 7. Доля суммарного количества АДНФГ и КДНФГ- относительно общего содержания карбонильных производных белков

При потреблении высококалорийной углеводно-жировой пищи у крыс 2-й и 3-й серий отмечалось увеличение активности процессов ОМБ, что проявлялось статистически значимым увеличением общего количества карбонильных производных белков по сравнению с интактной серией (рис. 6; *1-2 $\mathrm{p}=0,049 ;{ }^{*} 1-3 \mathrm{p}=0,047$ ). Увеличение площадей альдегиддинитрофенилгидразонов (АДНФГ)и кетондинитрофенилгидразонов (КДНФГ) ультрафиолетового (УФ) спектра характеризует степень повреждения аминокислотных остатков нейтрального характера. Увеличение площадей АДНФГ и КДНФГ видимого спектра аналогичным образом приводит к повреждению аминокислотных остатков основного характера [23]. Таким образом, ОМБ при алиментарном ожирении, моделируемом потреблением высококалорийной углеводно-жировой пищи, у крыс 2-й и 3-й серий осуществляется неспецифично, о чем говорят сравниваемые показатели ОМБ между сериями подопытных крыс (рис. 7). Кроме того, нами отмечено, что доля суммарного количества АДНФГ, являющихся первичными маркерами оксидативного стресса, относительно общего содержания карбонильных производных составляет более $80 \%$. Их накопление указывает на процесс фрагментации белков [24].

После введения суспензии мелатонина в дозе 2 мг/кг изменения уровня карбонильных производных не наблюдалось (рис. 6). По-видимому, данный результат объясняется необходимостью использования большей концентрации препарата и/или увеличения периода его экспозиции, что требует дальнейшего изучения.

\section{ОБСУЖДЕНИЕ}

Резюмируя полученные данные, следует отметить, что скармливание животным высококалорийного углеводно-жирового корма приводит к достаточно быстрому развитию ожирения у крыс, что обусловливает снижение физической работоспособности и устойчивости к тяжелой гипобарической гипоксической гипоксии вследствие изменения высоты стояния диафрагмы, уменьшения объема грудной полости, дистрофии скелетных мышц, в том числе и дыхательных. Неразрывно с увеличением массы тела и накоплением висцерального жира активизируются процессы свободнорадикального окисления, затрагивающие не только нарушение липидных структур, но и белков, причем повреждение аминокислот в их составе происходит неселективно. В качестве индукторов образования ОМБ могут выступать АФК $\left(\mathrm{OH}^{\circ}, \mathrm{O}_{2}{ }^{\circ}\right.$, $\mathrm{H}_{2} \mathrm{O}_{2}, \mathrm{O}_{2}$ ), активные формы азота (NO-, ONOO-], металлы переменной валентности $\left(\mathrm{Cu}^{2+}, \mathrm{Fe}^{2+}\right)$, продукты ПОЛ (ТБК-реактивные продукты (МДА), 4-гидрокси-2-ноненаль (ГНЕ)) [25]. МДА и ГНЕ являются наиболее распространенными продуктами взаимодействия липидов с АФК. МДА имеет в своей структуре две альдегидные группы, что обуславливает его взаимодействие с аминогруппами белков. ГНЕ может взаимодействовать с гистидином, лизином и цистеином, образуя циклические продукты, способные далее превращаться в карбонильные группы [26]. Влияние мелатонина на данные процессы реализуется несколькими механизмами. Свои цитопротективные свойства мелатонин реализует посредством как прямой способности связывать АФК вследствие образования различных биологически активных соединений, таких как $\mathrm{N}$-ацетилсеротонин, 5-метокситриптамин, $\mathrm{N}$-диметил-5-метокситриптамин, 5-метокситрифотол, циклический 2-гидроксимелатонин, пинолин и 5-метоксилированные кинурамины [27], так и посредством воздействия на мембранные и ядерные рецепторы, опосредованно влияющие на экспрессию генов ферментов антиоксидантной защиты [28]. Нами показано, что снижение ТБК-реактивных продуктов (в том числе МДА) не сопровождалось ослаблением процессов ОМБ, как ожидалось нами, что подтверждает наличие других инициаторов ОМБ при алиментарном ожирении. Также стоит отметить, что изменений в функциональной активности крыс после применения исследуемого препарата не наблюдалось, что говорит о низких в данной концентрации адаптивных возможностях мелатонина. Неспецифичный процесс ОМБ при алиментарном ожирении указывает на то, что окислительный стресс затрагивает большинство структур белков, инактивируя их. Но не совсем отчетливые результаты оценки влияния мелатонина на ОМБ, в отличие от положительного - параллельного эффекта на ПОЛ, возможно, связаны с необходимостью использования большей концентрации исследуемого препарата и/или увеличения периода его экспозиции.

\section{ЗАКЛЮЧЕНИЕ}

В последнее время изучение биохимической и физиологической активности гормона шишковидной железы - мелатонина интересует исследователей различных стран мира, что обусловлено достаточно широким спектром его биологических эффектов: выполнение роли антиоксиданта, регулятора функций всех без исключения клеток $[29,30]$ и т.д. Между тем изучение свойств мелатонина позволяет указать на несколько вероятных причин разноречивости результатов исследований его различных видов активности. К ним, в частности, могут относиться: видовые особенности экспериментальных животных, исходное функциональное состояние исследуемого организма, доза и способ введения мелатонина, возрастные различия [31, 32] и др. Особенно высок его антиоксидантный потенциал, который может быть использован в клинической практике, в том числе при алиментарном ожирении и ассоциированных с ним видах патологии. Однако вопросы изучения процессов и механизмов ОМБ при разных формах патологии остаются 
открытыми. Нами была показана важная роль гиперкалорийной пищи в развитии как алиментарного ожирения, так и изменении оксидативного статуса организма в сторону активации свободнорадикальных процессов, затрагивающих различные его структуры, в частности, приводящих к повреждению белковых молекул. Одновременно нами отмечено, что состояние белковых структур при ожирении более стабильное, а их повреждение неспецифичное и устойчивое к антиоксидантному воз- действию мелатонина. Это свидетельствует о высокой актуальности и необходимости дальнейшего изучения этого важного медико-биологического процесса.

\section{ДОПОЛНИТЕЛЬНАЯ ИНФОРМАЦИЯ}

Конфликт интересов. Авторы декларируют отсутствие явных и потенциальных конфликтов интересов, связанных с публикацией настоящей статьи.

\section{СПИСОК ЛИТЕРАТУРЫ | REFERENCES}

1. Бутрова С.А., Плохая А.А. Ожирение и сахарный диабет: общность этиологии и профилактики // Сахарный диабет. - 2005. - № 3. C.45-50. [Butrova S.A., Plokhaya A.A. Ozhirenie i sakharnyi diabet: obshchnost' etiologii i profilaktiki // Sakharnyi diabet. 2005;(3):45-50. (In Russ).]

2. Бородин Е.А., Бородина Г.П., Доровский В.А. и др. Перекисное окисление липидов в мембранах эритроцитов и микросом печени и антиокислительная система тканей крыс при длительном действии холода // Биологические мебраны. - 1992. - Т.9. - №6. C.622 - 627. [Borodin E.A., Borodina G.P., Dorovskii V.A. i dr. Perekisnoe okislenie lipidov $v$ membranakh eritrotsitov i mikrosom pecheni i antiokislitel'naya sistema tkanei krys pri dlitel'nom deistvii kholoda // Biologicheskie mebrany. 1992;9(6): 622 - 627. (In Russ).]

3. Chakravarti B., Chakravarti D.N. Oxidative Modification of Proteins: Age-Related Changes // Gerontology. 2007;53:128-139. doi:10.1159/000097865

4. Nystrom T. Role of oxidative carboxylation in protein quality control and senescence //The EMBO Journal. 2005;24(7):1311 - 1317. doi:10.1038/sj.emboj.7600599

5. Davies K. J. A., Delsignore M. E., Lin S. W. Protein Damage and Degradation by Oxygen Radicals // Journal of Biological Chemistry. 1987; 262(20): 9908 - 9913.

6. Дубинина Е.Е. Продукты метаболизма кислорода в функциональной активности клеток // СПб: Медицинская пресса, 2006. C. 400. [Dubinina E.E. Produkty metabolizma kisloroda $v$ funktsional'noi aktivnosti kletok // St. Petersburg: Meditsinskaya pressa; 2006. p. 400. (In Russ).]

7. Ernst A, Stolzing A, Sandig G, Grune T. Protein oxidation and the degradation of oxidized proteins in the rat oligodendrocyte cell line OLN 93-antioxidative effect of the intracellular spin trapping agent PBN. Mol Brain Res. 2004. doi: 10.1016/j.molbrainres.2003.12.005

8. Caraceni P., De Maria N., Ryu H.S. Et al. Colantoni A., Roberts L., Maidt M.L., Pye Q., Bernardi M., Van Thiel D.H., Floyd R.A. Proteins but not nucleic acids are molecular targets for the free radical attack during reoxygenation of rat hepatocytes //Free Radic. Biol. Med. 1997:23(2):339 - 344. doi:10.1016/S0891-5849(96)00571-0

9. Halliwell B. Reactive Oxygen Species and the Central Nervous System. J Neurochem. 1992. doi: 10.1111/j.1471-4159.1992.tb10990.x

10. Agarwal S., Sohal R.S. Differential oxidative damage to mitochondrial proteins during aging // Mech. Ageing. Dev. 1995; 85(1):55 - 63. doi:10.1016/0047-6374(95)01655-4

11. Forster M.J., Dubey A., Dawson K.M., Stutts W.A., Lal H., Sohal R.S. Age-related losses of cognitive function and motor skills in mice are associated with oxidative protein damage in the brain // Proc. Natl. Acad. Sci. 1996;93(10):4765 - 4769. doi:10.1073/pnas.93.10.476.5

12. Арапова А.И., Фомина M.A. Изучение влияния L-карнитина на изменение активности катепсинов B, L, Н и окислительной модификации белков в мышечных органах крыс // Российский медико-биологический вестник имени академика И.П. Павлова. - 2016 г. - T. 24. - №2. - C.13-20. [Arapova A.I., Fomina M.A. Izuchenie vliyaniya L-karnitina na izmenenie aktivnosti katepsinov B, L, H i okislitel'noj modifikacii belkov v myshechnyh organah krys // Rossijskij mediko-biologicheskij vestnik imeni akademika I.P. Pavlova. 2016; 24(2):13-20 (In Russ).]

13. Александрова Л.Н., Анисимов В.Н., Арушанян Э.Б. и др. Мелатонин: перспективы применения в клинике // под ред. Рапопорт С.И. - М.: ИМА-ПРЕСС, 2012. - С.176. [Aleksandrova L.N., Anisimov V.N., Arushanyan E.B. I dr. Melatonin: perspektivy primeneniya $\vee$ klinike // in. Rapoport S.I. Moscow: IMA-PRESS; 2012 p.176. (In Russ).]
14. Reiter R.J., Acuna-Castroviejo D.,Tan D.X. Free radical mediated molecular damage mechanisms for the Protective Actions of Melatonin in the Central Nervous System // An. N.Y. Acad. Sci. 2001;939:200-215. doi:10.1111/j.1749-6632.2001.tb03627.x

15. C. Rodriguez, J.C. Mayo, R.M. Sainz. Regulation of antioxidant enzymes: a significant role for melatonin // Jour. Pin. Res. 2004;36(1):1-9. doi:10.1046/j.1600-079x.2003.00092.x

16. Никоноров А.А., Тиньков А.А., Железнов Л.М. И др. Методический подход к изучению ожирения в эксперименте // Оренбург: ОАО «ИПК «Южный Урал», 2013. - С. 240. [Nikonorov A.A., Tin'kov A.A., Zheleznov L.M. At al. Metodicheskii podkhod k izucheniyu ozhireniya v eksperimente // Orenburg: OAO «IPK «Yuzhnyi Ural»; 2013. p.240 (In Russ).]

17. Дубинина Е.Е., Бурмистров С.О., Ходов Д.А. И др. Окислительная модификация белков сыворотки крови человека, метод её определения // Вопросы медицинской химии. - 1995. -Т.41. - № 1. C. 24-26. [Dubinina E.E., Burmistrov S.O., Khodov D.A. At al. Oxidative modification of human serum proteins. A method of determining it // Vopr. Med. Khim. 1995;41(1):24 - 26. (In Russ).]

18. Конюхова С.Г., Маркин С.Г., Конюхова А.А., и др. Перекисное окисление липидов и методы определения продуктов липопероксидации в биологических средах // Лабораторное дело. - 1989. - № 9. C. 40-46. [Konyukhova S.G., Markin S.G., Konyukhova A.A. At al. Perekisnoe okislenie lipidov i metody opredeleniya produktov lipoperoksidatsii v biologicheskikh sredakh // Laboratornoe delo. 1989;(9):40 - 46. (In Russ).]

19. Ильичева А.С., Фомина М.А., Медведев Д.В. Характеристика продуктов окислительного повреждения белков миокарда на фоне гипергомоцистеинемии // Наука молодых. - 2014. -№4. - С.37 43. [II'icheva A.S., Fomina M.A., Medvedev D.V. Characteristic products of oxidative damage of proteins in heart muscle with hyperhomocysteinemia // ERUDICIO JUVENIUM. 2014;(4):37 - 43. (In Russ).]

20. Давыдов В.В., Медведев Д.В., Шодиев Д.Р., Некрасова М.С. Влияние нарушения светового режима на липидный обмен и функциональные показатели у интактных крыс и животных с алиментарным ожирением // Наука молодых. - 2017. - Т.5. - №2. C.175 - 184. [Davydov V.V., Medvedev D.V., Shodiev D.R., Nekrasova M.S. Effect of light regimes violations on lipid metabolism in infact rats and animals with alimentary obesity // ERUDICIO JUVENIUM. 2017:5(2):175-184. (In Russ).] doi: 10.23888/HMJ20172175-184

21. Alexander J.K., Turell D.J., Drew M.J. Mechanisms of dyspnea in obesity // Cardiovasc. Res. Cent. Bull.1963;16:27 - 32

22. Gulcin, I.; Beydemir, S.; Hisar, O.; Koksal, E.; Reiter, R.J. Melatonin administration increases antioxidant enzymes activities and reduces lipid peroxidation in the rainbow trout (Oncorhynchus mykiss, Walbaum) erythrocytes // Turk. J. Vet. Anim. Sci., 2009, 33(3):241-245.

23. Фомина М.А., Абаленихина Ю.В. Способ комплексной оценки содержания продуктов окислительной модификации белков в тканях и биологических жидкостях: методические рекомендации; ГБОУ ВПО РязГМУ Минздрава. - Рязань: РИО РязГМУ, 2014. - С.60. [Fomina M.A., Abalenikhina Yu.V. Sposob kompleksnoi otsenki soderzhaniya produktov okislitel'noi modifikatsii belkov v tkanyakh i biologicheskikh zhidkostyakh: metodicheskie rekomendatsii; GBOU VPO RyazGMU Minzdrava. Ryazan': RIO RyazGMU; 2014; p.60. (In Russ).]

24. Baraibar M.A., Ladouce R., Friguet B. Proteomic quantification and identification of carbonylated proteins upon oxidative stress and during cellular aging // Journal of Proteomics. 2013;92:67-70. doi:10.1016/j.jprot.2013.05.008

25. Vasil'ev Y. V. et al. Protein modifications by electrophilic lipoxidation products: Adduct formation, chemical strategies and tandem mass spectrometry for their detection and identification // Mass Spectrom- 
etry Reviews. 2013;33(3):157 - 182. doi: 10.1002/mas.21389

26. Albarran M.T., Lopez-Burillo S, Pablos M.I. et al. Endogenous rhythms of melatonin, total antioxidant status and superoxide dismutase activity in several tissues of chick and their inhibition by light // Journal of Pineal Research. 2001;30(4):227-233 doi:10.1034/j.1600-079x.2001.300406.x

27. Dun-Xian Tan, Russel J. Reiter et al. Kynuramines, metabolites of melatonin and other indoles: the resurrection of an almost forgotten class of biogenic amines // Journal of Pineal Research. 2009;47(2):109 - 126. doi:10.1111/j.1600-079x.2009.00701.x

28. Carmen Rodriguez, Juan C. Mayo et al. Regulation of antioxidant enzymes: a significant role for melatonin // Journal of Pineal Research. 2004; 36:1-9. doi:10.1046/j.1600-079X.2003.00092.x
29. Bahr I., Muhlbauer E., Schulte H. et al. Melatonin stimulates glucagon secretion in vitro and in vivo // Journal of Pineal Research 2011;50:336 - 344. doi: 10.1111/j.1600-079X.2010.00848.x

30. Peschke E, Mühlbauer E. New evidence for a role of melatonin in glucose regulation. Best Pract Res Clin Endocrinol Metab. 2010 doi: 10.1016/j.beem.2010.09.001

31. Darul K, Kruczyńska H. Effect of melatonin on biochemical variables of the blood in dairy cows. Acta Vet Hung. 2004;52(3):361-367. doi: 10.1556/AVet.52.2004.3.11

32. Cagnacci A, Arangino S, Renzi A, et al. Influence of melatonin administration on glucose tolerance and insulin sensitivity of postmenopausal women. Clin Endocrinol (Oxf). 2001. doi: 10.1046/j.1365-2265.2001.01232.x

\section{ИНФОРМАЦИЯ ОБ АВТОРАХ [AUTHORS INFO]}

*Шодиев Дмитрий Рахимович, студент [Dmitry R. Shodiev, student], адрес: Россия, 390005 Рязань, ул.Высоковольтная 9 [address: Russia, 390005 Ryazan, st.Vysokovoltnaya 9]; eLibrary SPIN: 3556-4398; e-mail: shodiev.dima@yandex.ru

Давыдов Виктор Викторович, д.м.н., профессор [Victor V. Davydov, ScD, Professor]; https://orcid.org/0000-0002-9292-1215; eLibrary SPIN: 1356-7511; e-mail: davydov.vikt@yandex.ru Медведев Дмитрий Валерьевич, ассистент кафедры[Dmitry V. Medvedev, assistant of the department]; https://orcid. org/0000-0002-8181-7703; eLibrary SPIN: 6785-8762; e-mail: meddmit@mail.ru

Некрасова Марина Сергеевна, студентка [Marina S. Nekrasova, student]; eLibrary SPIN: 2035-8060;

e-mail: marina.nekrasova.95@mail.ru

\section{ЦИТИРОВАТЬ:}

Давыдов В.В., Медведев Д.В., Шодиев Д.Р., Некрасова М.С. Влияние экзогенного мелатонина на оксидативный статус И состояние перекисного окисления белков у крыс с моделью алиментарного ожирения // Ожирение и метаболизм. - 2018. - T.15. - No. 4 - С. 15-21. doi: 10.14341/OMET9561

\section{TO CITE THIS ARTICLE:}

Davydov VV, Medvedev DV, Shodiev DR, Nekrasova MS. Influence of exogenous melatonin on the oxidative status and the state of peroxidation of proteins in a rat model of alimentary obesity. Obesity and metabolism. 2018;15(4): 15-21. doi: 10.14341/OMET9561 